The Egyptian Journal of Hospital Medicine (April 2019) Vol. 75 (1), Page 2092-2097

\title{
The Effect of Shock Wave Therapy as a New Modality for Treatment of Primary Knee Osteoarthritis
}

\author{
Safaa Shebl El-Sakka*, Mervat Ismail Hussein, Amal Mohamad El-Barbary, Fahema Saad Rehan \\ Department of Physical Medicine, Rheumatology and Rehabilitation \\ Faculty of Medicine, Tanta University \\ *Corresponding author: Safaa Shebl El-Sakka, Mobile: (+20)01098697188, E-Mail: safaaelsakka@yahoo.com
}

\begin{abstract}
Background: osteoarthritis, the most common form of arthritis, is a chronic disease characterized by slow degradation of cartilage, pain, and increasing disability.

Objective: to study the effect of shock wave therapy in treatment of primary knee osteoarthritis.

Patients and Methods: thirty patients with primary knee osteoarthritis were classified equally into 2 groups according to the line of treatment; Group I received extra-corporeal shock wave therapy and Group II received continuous ultrasonic waves. Patients were evaluated for pain using visual analogue scale, active range of motion, and physical and functional assessment. Bilateral anteroposterior weight bearing radiographs were done for all patients before treatment and degree of osteoarthritis was assessed by Kallgren and Lawrence Radiographic criteria.

Results: there was significant improvement in group I more than group II (as regard to pain assessed by visual analogue scale (VAS) after treatment ( $\mathrm{p}=0.039)$ and in follow up ( $\mathrm{p}<0.001)$. There was significant improvement in morning stiffness in both groups with insignificant difference between both them. Regarding active range of motion (ROM), there was significant improvement in flexion in both groups with significant difference between both groups before and after treatment $(\mathrm{p}=0.001)$ and in follow up ( $\mathrm{p}<0.001)$. Regarding chair stand test, there was significant improvement in both groups with in significant difference between them. Regarding stair climb test (SCT), there was significant improvement in both groups with insignificant difference between them.

Conclusions: shock wave had an effect in treatment of primary knee OA as a new modality for improving clinical and functional performance.
\end{abstract}

Keywords: Primary knee osteoarthritis; shock wave therapy; therapeutic ultrasound.

\section{INTRODUCTION}

Osteoarthritis (OA), the most common form of arthritis, is a chronic disease characterized by slow deterioration of cartilage, pain and increased disability (1). The aim in treatment of OA is to reduce pain and other symptoms, increase health related quality of life and normalize patient's limited daily activity ${ }^{(2)}$.

There are several options for treating osteoarthritis of the knee, including simple analgesics, non-steroidal anti-inflammatory drugs (NSAIDS), intraarticular injection of glucocorticoids, physiotherapy, and total knee replacement ${ }^{(3)}$.

Extracorporeal shock wave therapy (ESWT) was first used to break kidney stones. Its use was proposed for musculoskeletal disorders as the result of an incidental observation of an osteoblastic response pattern, during animal studies, in the late $1980 \mathrm{~s}^{(\mathbf{4})}$.

In recent years, ESWT has been widely used for pain relief and the treatment of musculoskeletal disorders, such as epicondylitis, plantar fasciitis, calcific tendinitis, and osteoarthritis ${ }^{(5,6)}$.

\section{AIM OF THE WORK}

The aim of this work is to study the effect of shock wave therapy as a new modality in treatment of primary knee osteoarthritis and its effect on clinical and functional outcome.

\section{PATIENTS AND METHODS}

This study included 30 patients with symptomatic primary knee osteoarthritis. They were collected from the outpatient clinic of Physical Medicine, Rheumatology \& Rehabilitation Department, Tanta University Hospitals. The patients were diagnosed according to American College of Rheumatology(7) criteria for classification and diagnosis of osteoarthritis. The study was approved by the Ethics Board of Tanta University and an informed written consent was taken from each participant in the study.

Patients were classified equally into 2 groups according to the line of treatment; Group I: The patients received extra-corporeal shock wave therapy, once weekly for three weeks, every session used radial and focus heads. Radial head 1000 shocks per session, 2.5$4 \mathrm{~mJ} / \mathrm{mm}^{2}$, frequency of pulses $8 \mathrm{~Hz}$, and focus head 1000 shocks persession, $0.15 \mathrm{MJ} / \mathrm{mm} 2$ and frequency of pulses $6 \mathrm{~Hz}^{(8)}$. Site of application of radial head: Around knee joint line. Site of application of focus head: 
The Effect of Shock Wave Therapy as a New Modality...

On the most tender point in the joint line ${ }^{(8)}$. The patients were recommended to make ice packs after session and not to take any analgesics or anti-inflammatory drugs. Group II: The patients received continuous ultrasonic waves of $1 \mathrm{MHz}$ frequency and 1 watt $/ \mathrm{cm} 2$ power. The session lasted for 10 minutes. Sessions were 3 per week for 3 weeks using ultrasound gel as a coupling medium $^{(9)}$.

All patients practiced home exercise therapy (isometric) for the knee 5 times/day ${ }^{(10)}$. All patients were assessed before, after one week of treatment and after one month of treatment as a follow up period. The study was approved by the ethical committee of Tanta University Hospital. All patients gave their informed consent prior to their inclusion. Patients of both groups were subjected to complete history taking, body mass index (BMI), clinical evaluation (Pain: It was assessed using visual analogue scale (VAS) ${ }^{(11)}$, active range of motion (ROM) ${ }^{(12)}$, measures of physical performance assessments: using Chair Stand Test (CST), Stair Climb Test (SCT), Six-Minute Walk Test (6MWT) ${ }^{(13)}$, functional assessment using WOMAC index ${ }^{(14)}$ and radiological assessment were done for all patients before treatment using Kallgren and Lawrence ${ }^{(15)}$ Radiographic criteria for assessment of degree of osteoarthritis.

\section{Statistical analysis of the data ${ }^{(16,17)}$}

Data were fed to the computer and analysed using IBM SPSS software package version 20.0. (Armonk, NY: IBM Corp) Qualitative data were described using number and percent. The Kolmogorov-Smirnov test was used to verify the normality of distribution Quantitative data were described using range (minimum and maximum), mean, standard deviation and median. Significance of the obtained results was judged as p level $\leq 0.05$.

\section{Results}

Demographic data of the two studied groups were demonstrated in Table (1), most of our patients were house wives (33.3\% in group I and $53.3 \%$ in group II). The comparison between the two studied groups regarding clinical assessment was demonstrated in table (2).

There was significant improvement in group I more than group II as regard to pain assessed by visual analogue scale after treatment and in follow up.

There was insignificant difference between both groups as regard to morning stiffness. Regarding to active flexion, there was significant improvement in group I after treatment compared to before treatment and in follow up compared to before treatment. While in group II, there was significant improvement after treatment compared to before treatment, and in follow up compared to before treatment in addition to follow up compared to after treatment. Functional assessment was demonstrated in table (3).

There was significant improvement in results of 6-minute walk test in group I after treatment and in follow up. There was insignificant difference between both studied groups as regard to chair stand test, stair climb test and WOMAC.

Comparison between the two studied groups regarding to plain radiography ${ }^{(\mathbf{1 5})}$ is demonstrated in table (4), there was insignificant difference between both groups.

Table (1): Demographic data of the two studied groups

\begin{tabular}{|c|c|c|c|c|c|}
\hline Data & \multicolumn{2}{|c|}{$\begin{array}{l}\text { Group I (Shock wave) } \\
(\mathrm{n}=15)\end{array}$} & \multicolumn{2}{|c|}{$\begin{array}{l}\text { Group II (Ultrasound) } \\
(n=15)\end{array}$} & $\mathrm{P}$ \\
\hline Age & \multicolumn{2}{|c|}{$53.47 \pm 7.76$} & \multicolumn{2}{|c|}{$51.53 \pm 5.74$} & 0.445 \\
\hline $\begin{array}{l}\text { Sex: } \\
\text { Male/female }\end{array}$ & $\begin{array}{l}6 / 9 \\
\text { (number) }\end{array}$ & $\begin{array}{l}40.0 / 60.0 \\
\text { (percent) }\end{array}$ & $\begin{array}{l}3 / 12 \\
\text { (number) }\end{array}$ & $\begin{array}{l}20.0 / 80.0 \\
\text { (percent) }\end{array}$ & $\begin{array}{l}\text { FEp }=0.42 \\
7\end{array}$ \\
\hline Body mass index $(\mathrm{kg} / \mathrm{m} 2)$ & \multicolumn{2}{|c|}{$35.30 \pm 5.30$} & \multicolumn{2}{|c|}{$36.35 \pm 3.10$} & 0.513 \\
\hline Duration of illness & \multicolumn{2}{|c|}{$2.94 \pm 2.58$} & \multicolumn{2}{|c|}{$4.83 \pm 3.51$} & $0.029 *$ \\
\hline $\begin{array}{l}\text { Side of affection }(\mathrm{Rt} / \mathrm{Lt}) \\
\%\end{array}$ & \multicolumn{2}{|l|}{$\begin{array}{l}8 / 7 \\
53.3 / 46.7\end{array}$} & \multicolumn{2}{|c|}{$\begin{array}{l}11 / 4 \\
73.3 / 26.7\end{array}$} & 0.256 \\
\hline
\end{tabular}

Data were presented as Mean \pm SD 
Table (2): Comparison between the two studied groups regarding to clinical assessment

\begin{tabular}{|c|c|c|c|}
\hline \multirow{2}{*}{$\begin{array}{l}\text { Data } \\
\text { Pain (vas) }\end{array}$} & Group I & Group II & $\mathbf{P}$ \\
\hline & \multicolumn{2}{|c|}{ Before treatment } & \multirow[t]{2}{*}{0.796} \\
\hline \multirow{5}{*}{ Mean \pm SD } & $7.73 \pm 1.67$ & $7.87 \pm 1.06$ & \\
\hline & \multicolumn{2}{|l|}{ After treatment } & \multirow[t]{2}{*}{$0.039 *$} \\
\hline & $5.80 \pm 1.61$ & $6.87 \pm 0.99$ & \\
\hline & \multicolumn{2}{|l|}{ Follow up } & \multirow[t]{2}{*}{$<0.001 *$} \\
\hline & $3.87 \pm 1.36$ & $6.0 \pm 1.20$ & \\
\hline $\mathbf{P}$ in each group & $\begin{array}{l}\text { p1<0.001* } \\
\text { p2<0.001* } \\
\text { p3<0.001* }\end{array}$ & $\begin{array}{l}\mathrm{p} 1<0.001 * \\
\mathrm{p} 2<0.001 * \\
\mathrm{p} 3=0.001^{*}\end{array}$ & \\
\hline \multirow{2}{*}{$\begin{array}{l}\text { Morning stiffness } \\
\text { (in minutes) }\end{array}$} & \multicolumn{2}{|c|}{ Before treatment } & \multirow[t]{2}{*}{0.164} \\
\hline & $5.13 \pm 3.42$ & $10.33 \pm 14.32$ & \\
\hline \multirow{4}{*}{ Mean \pm SD } & \multicolumn{2}{|l|}{ After treatment } & \multirow[t]{2}{*}{0.136} \\
\hline & $3.47 \pm 2.70$ & $7.07 \pm 9.65$ & \\
\hline & \multicolumn{2}{|l|}{ Follow up } & \multirow[t]{2}{*}{0.157} \\
\hline & $1.80 \pm 1.78$ & $4.93 \pm 7.50$ & \\
\hline$P$ in each group & $\begin{array}{l}\text { p1 }=0.055 \\
\text { p2<0.001* } \\
\text { p3 }=0.055\end{array}$ & $\begin{array}{l}\text { p1 }=0.022^{*} \\
\text { p2<0.001* } \\
\text { p3 }=0.083\end{array}$ & \\
\hline \multirow[t]{6}{*}{ Active flexion } & \multicolumn{2}{|c|}{ Before treatment } & \multirow[t]{2}{*}{$0.001 *$} \\
\hline & $98.53 \pm 12.48$ & $71.33 \pm 24.82$ & \\
\hline & \multicolumn{2}{|l|}{ After treatment } & \multirow[t]{2}{*}{$0.001 *$} \\
\hline & $105.07 \pm 11.88$ & $83.40 \pm 17.10$ & \\
\hline & \multicolumn{2}{|l|}{ Follow up } & \multirow[t]{2}{*}{$<0.001 *$} \\
\hline & $112.47 \pm 12.20$ & $89.27 \pm 18.15$ & \\
\hline$P$ in each group & $\begin{array}{l}\text { p1<0.001* } \\
\text { p2<0.001* } \\
\text { p3 }=0.121\end{array}$ & $\begin{array}{l}\text { p1 }=0.003^{*} \\
\text { p2<0.001* } \\
\text { p3 }=0.028^{*}\end{array}$ & \\
\hline
\end{tabular}

$\mathrm{p} 1$ : $\mathrm{p}$ value for comparing between before treatment and after treatment

p2: $p$ value for comparing between before treatment and follow up

p3: $\mathrm{p}$ value for comparing between after treatment and follow up

*: Statistically significant at $\mathrm{p} \leq 0.05$ 
Table (3): Comparison between both groups regarding to Functional assessment

\begin{tabular}{|c|c|c|c|}
\hline Data & Group I & Group II & $\begin{array}{l}\mathbf{P} \text { (group I versus } \\
\text { group II) }\end{array}$ \\
\hline \multirow{6}{*}{$\begin{array}{l}\text { CST } \\
\text { Mean } \pm \text { SD. }\end{array}$} & \multicolumn{2}{|c|}{ Before treatment } & \multirow{2}{*}{0.438} \\
\hline & $8.33 \pm 5.50$ & $8.87 \pm 4.94$ & \\
\hline & \multicolumn{2}{|l|}{ After treatment } & \multirow[t]{2}{*}{0.256} \\
\hline & $9.13 \pm 5.79$ & $9.73 \pm 4.53$ & \\
\hline & \multicolumn{2}{|l|}{ Follow up } & \multirow[t]{2}{*}{0.983} \\
\hline & $10.13 \pm 5.25$ & $10.13 \pm 5.08$ & \\
\hline $\mathbf{P}$ in each group & $\begin{array}{l}\text { p1 }=0.201 \\
\text { p2 }=0.001^{*} \\
\text { p3 }=0.036^{*}\end{array}$ & $\begin{array}{l}\mathrm{p} 1=0.022^{*} \\
\mathrm{p} 2=0.001 * \\
\mathrm{p} 3=0.235\end{array}$ & \\
\hline \multirow{6}{*}{$\begin{array}{l}\text { SCT } \\
\text { Mean } \pm \text { SD. }\end{array}$} & \multicolumn{2}{|c|}{ Before treatment } & \multirow[t]{2}{*}{0.917} \\
\hline & $12.47 \pm 9.25$ & $9.40 \pm 3.25$ & \\
\hline & \multicolumn{2}{|l|}{ After treatment } & \multirow[t]{2}{*}{0.868} \\
\hline & $10.80 \pm 8.87$ & $8.0 \pm 2.52$ & \\
\hline & \multicolumn{2}{|l|}{ Follow up } & \multirow[t]{2}{*}{0.950} \\
\hline & $9.87 \pm 8.43$ & $7.01 \pm 2.08$ & \\
\hline$P$ in each group & $\begin{array}{l}\text { p1 }=0.003^{*} \\
\text { p2<0.001* } \\
\text { p3 }=0.171\end{array}$ & $\begin{array}{l}\text { p1 }=0.008^{*} \\
\text { p2<0.001* } \\
\text { p3 }=0.036^{*}\end{array}$ & \\
\hline \multirow[t]{3}{*}{ 6MWT } & \multicolumn{2}{|c|}{ Before treatment } & \multirow[t]{2}{*}{0.109} \\
\hline & $262.63 \pm 81.78$ & $226.13 \pm 78.30$ & \\
\hline & \multicolumn{2}{|l|}{ After treatment } & \multirow[t]{2}{*}{$0.020 *$} \\
\hline \multirow[t]{3}{*}{ Mean \pm SD } & $284.31 \pm 82.52$ & $230.33 \pm 77.70$ & \\
\hline & \multicolumn{2}{|l|}{ Follow up } & \multirow[t]{2}{*}{$0.014 *$} \\
\hline & $295.60 \pm 80.87$ & $237.13 \pm 78.98$ & \\
\hline$P$ in each group & $\begin{array}{l}\text { p1 }=0.028^{*} \\
\text { p2<0.001* } \\
\text { p3 }=0.014^{*}\end{array}$ & $\begin{array}{l}\text { p1 }=0.315 \\
\text { p2<0.001* } \\
\text { p3 }=0.001 *\end{array}$ & \\
\hline \multirow[t]{2}{*}{ WOMAC } & \multicolumn{2}{|c|}{ Before treatment } & \multirow[t]{2}{*}{0.950} \\
\hline & $54.33 \pm 18.17$ & $55.07 \pm 17.20$ & \\
\hline \multirow[t]{4}{*}{ Mean \pm SD } & \multicolumn{2}{|l|}{ After treatment } & \multirow[t]{2}{*}{0.803} \\
\hline & $41.40 \pm 17.32$ & $44.73 \pm 15.93$ & \\
\hline & \multicolumn{2}{|l|}{ Follow up } & \multirow[t]{2}{*}{0.152} \\
\hline & $25.13 \pm 14.60$ & $32.80 \pm 11.99$ & \\
\hline$P$ in each group & $\begin{array}{l}\text { p1 }=0.018^{*} \\
\text { p2<0.001* } \\
\text { p3 }=0.003^{*}\end{array}$ & $\begin{array}{l}\text { p1 }=0.006^{*} \\
\text { p2<0.001* } \\
\text { p3 }=0.006^{*}\end{array}$ & \\
\hline
\end{tabular}

$\mathrm{p} 1: \mathrm{p}$ value for comparing between before treatment and after treatment

$\mathrm{p} 2$ : $\mathrm{p}$ value for comparing between before treatment and follow up

p3: $\mathrm{p}$ value for comparing between after treatment and follow up

*: Statistically significant at $\mathrm{p} \leq 0.05$ 
Safaa El-Sakka et al.

Table (4): Comparison between the two studied groups regarding to radiological assessment using plain radiography (K.\&L.)

\begin{tabular}{|c|c|c|c|c|c|c|}
\hline \multirow{2}{*}{$\begin{array}{l}\text { Plain Radio-graghy } \\
\text { (K.\&L.) }\end{array}$} & \multicolumn{2}{|c|}{ Group I $(n=15)$} & \multicolumn{2}{|c|}{ Group II $(n=15)$} & \multirow[t]{2}{*}{$\mathbf{X}^{2}$} & \multirow[t]{2}{*}{ MCp } \\
\hline & No. & $\%$ & NO. & $\%$ & & \\
\hline \multicolumn{7}{|c|}{ Before treatment } \\
\hline GradeII & 5 & 26.7 & 9 & 60.0 & \multirow[t]{2}{*}{2.143} & \multirow[t]{2}{*}{0.143} \\
\hline Grade III & 10 & 66.7 & 6 & 33.3 & & \\
\hline \multicolumn{7}{|c|}{ After treatment } \\
\hline Grade II & 5 & 26.7 & 9 & 60.0 & \multirow[t]{2}{*}{2.143} & \multirow[t]{2}{*}{0.143} \\
\hline Grade III & 10 & 66.7 & 6 & 33.3 & & \\
\hline \multicolumn{7}{|c|}{ Follow up } \\
\hline Grade II & 5 & 26.7 & 9 & 60.0 & \multirow[t]{2}{*}{2.143} & \multirow[t]{2}{*}{0.143} \\
\hline Grade III & 10 & 66.7 & 6 & 33.3 & & \\
\hline
\end{tabular}

\section{DISCUSSION}

Extracorporeal shock wave therapy (ESWT) is considered one of the most effective techniques that helps in treatment of renal calculi and recently used in treatment of knee osteoarthritis as it induces neovascularization and up-regulation of angiogenesis and osteogenesis related growth factors that lead to bone and joint remodeling ${ }^{(18)}$. In our study; there was significant improvement of clinical assessment including pain and active range of motion in group I (received shock wave) more than group II( received ultrasound) and these results were in agreement with Kim et $\boldsymbol{a l}_{\mathbf{}^{(19)}}$ who did a study on osteoarthritis patients and showed greater improvement in regard to relieving pain and restoring functional outcome (Table 2).

However, the exact mechanisms of shock wave, on knee OA, are complex and have not been clearly explained, the mechanism of pain and tenderness improvement by shock wave may be due to that the shock wave causes selective dysfunction of sensory unmyelinated nerve fibers. It is known to improve the symptoms of OA via an inflammatory response by the secretion of growth factors also to repair damaged tissues by encouraging angiogenesis ${ }^{(20)}$. Our results were in agreement with Chen et $\boldsymbol{a l l}^{(\mathbf{2 0 )}}$ who did randomized, controlled study on one hundred and twenty patients with bilateral moderate knee osteoarthritis were selected and randomly assigned to four groups. Patients in Groups I\&III received isokinetic muscular strengthening exercises three times weekly for 8 weeks. Group II received pulse ultrasound treatment for popliteal three times weekly for 8 weeks, Group III received weekly shock wave therapy for popliteal for the first 6 weeks, and Group IV acted as controls. Comparison of the results in treated Groups I-III showed that the addition of either ultrasound treatment (Group II) or shock wave (Group III) had better therapeutic effects in reduction of knee pain, inactivity, and increase in range of motion and muscle peak torques. Our results were in agreement with Imamura et $\boldsymbol{a l}^{\left({ }^{(\mathbf{8})}\right.}$ regarding physical performance and functional assessment there was significant improvement in group I (treated by shock wave) with insignificant difference between the two groups except 6MWT. The results of the current study in group I were in disagreement with Imamura $\boldsymbol{e t} \boldsymbol{a l}^{(\mathbf{( 2 1 )}}$ who did a randomized, placebo-controlled trial on a total of 105 women with disabling pain due to primary knee osteoarthritis lasting for a mean of 103 months to assess the efficacy and safety of radial extracorporeal shock wave therapy (rESWT) for disabling pain due to primary knee osteoarthritis. Their patients received either rESWT (3 sessions, each one week apart, 2,000 rESWT impulses per session, positive energy flux density $(0.10$ $0.16 \mathrm{~mJ} / \mathrm{mm} 2$ ) or placebo treatment. Their results showed that by comparing with placebo treatment, rESWT led to a statistically significant improvement only in mean WOMAC scores for pain and a few of the pressure measurements. Table (2)

Regarding active range of motion (ROM), in group I, our results showed that there was significant improvement in flexion in group I compared to group II. Table (2)

The results of improvement in shock wave treated group were in agreement with Lee $\boldsymbol{e t} \boldsymbol{a l} .{ }^{(22)}$ who did a study on 20 patients with knee osteoarthritis to identify the effect of shock wave therapy on pain and function of knee joint. Patients were divided into a conservative physical therapy group $(\mathrm{n}=10)$ and an extracorporeal shock wave therapy group $(n=10)$. Both groups received general conservative physical therapy both groups were treated three times a week over a four-week period. They found statistically difference in results of comparison between both groups regarding the improvement of pain and function. Regarding WOMAC, both studied groups had significant improvement after treatment compared to before treatment and in follow up compared to before 
treatment also in follow up compared to after treatment $(\mathrm{P}$ $>0.05)$, with insignificant difference between them (Table 2) and these results were in agreement with Elerian et al. ${ }^{(23)}$, the improvement of physical performance in shock wave group may be due to that SWT induced the growth of neovascularization which play a role to improve blood supply and tissue regeneration at bone tendon junction and this leads to improvement in joint performance and this was in agreement with Wang et $\boldsymbol{a l}^{\left({ }^{(24)}\right.}$ regarding plain radiography $(K \& L)$, there was insignificant difference between both studied groups $(\mathrm{P}>0.05)$.Table $(3)$

\section{CONCLUSIONS}

Shock wave had an effect in treatment of primary knee OA as a new modality for improving clinical and functional performance.

\section{REFERENCES}

1. Moreland LW (2003): Intra-articular hyaluranon (hyaluronic acid) and hylans for the treatment of osteoarthritis: mechanisms of action. Arthritis Res Ther., 5:54-67.

2. Fernandes L, Hagen KB, Biglsma JW et al. (2013): EULAR recommendations for the non-pharmacological core management of hip and knee osteoarthritis. Ann Rheum Dis., 72(7):1125-35.

3. Wang CT, Lin J, Chang CG et al. (2004): Therapeutic effects of hyaluronic acid on osteoarthritis of the knee. J B J S., 86(3):538-45.

4. Wang CJ (2012): Extracorporeal shock wave therapy in musculoskeletal disorders. J OrthopSurg Res., 7:11-16.

5. Wang C, Yang K, Wang F et al. (2003): Shock wave therapy for calcific tendinitis of shoulder: a prospective clinical clinical study with two-year follow up. A M J Sports Med., (31):425-30.

6. Rompe JD, Theis $\mathbf{C}$ and Maffulli $\mathbf{N}$ (2005): Shock wave treatment for tennis elbow. Der Orthopade., 34(6):567-70.

7. Ma J, Niu D, Wan N et al. (2015): Elevated chemerin levels in synovial fluid and synovial membrane from patients with knee osteoarthritis. Int J ClinExpPathol., 8(10): 13393-1998.

8. Imamura M, Alfieri FM, Plapler PG et al. (2015): Influence of shockwave therapy on pain in women with knee osteoarthritis, ActaFisiatr., 22(2):84-86.

9. Kozanoglu E, Basaran S, Guzel R et al. (2003): Short term efficacy of ibuprofen phonophoresis versus continuous ultrasound therapy in knee osteoarthritis. Swiss Med Wkly., 133: 333-338.

10. Sen A, Gocen Z, Unver B et al. (2004): The frequency of visits by the physiotherapist of patients receiving homebased exercise therapy for knee osteoarthritis. The knee, 11(2):151-153.
11. Klimek L, Bergmann K-C, Biedermann T et al. (2017): Visual analogue scales (VAS): Measuring instruments for the documentation of symptoms and therapy monitoring in cases of allergic rhinitis in everyday health care. Allergo J Int., 26(1):1624.

12. Volpi P (2016): Arthroscopy and Sport Injuries: Applications in High-level Athletes. Springer International Publishing Switzerland.

13. Bennell KL and Hinman RS (2011): A review of the clinical evidence for exercise in osteoarthritis of the hip and knee. J Sci Med Sport, 14(1):4-9.

14. Guermazi M, Poiraudeau S, Yehia M et al. (2004): Translation, adaptation and validation of the Western Ontario and McMaster Universities Osteoarthritis Index(WOMAC) for an Arab Population Osteoarthritis Research Society International, 12:459-68.

15. Bach BR, Jones GT, Hager CA et al. (1995): Arthrometric results of arthroscopically assisted anterior cruciate ligament reconstruction using autograft patellar tendon substitusion. Am J Sports Med., 23(2):179-85.

16. Kotz S, Balakrishnan N, Read $\mathrm{C}$ et al. (2006): Encyclopedia of statistical sciences. 2nd ed., Hoboken, N.J.: Wiley Interscience. https://www.wiley.com/enus/Encyclopedia+of+Statistical+Sciences\%2C+16+Volu me+Set\%2C+2nd+Edition-p-9780471150442

17. Kirkpatrick LA and Feeney BC (2013): Simple guide to IBM SPSS statistics for version 20.0. Student ed. Belmont, Calif.: Wadsworth, Cengage Learning. https://www.amazon.com/Simple-Guide-IBM-SPSSVersion/dp/1285086015

18. Wang CJ, Ko JY, Weng LH et al. (2010): Extracorporeal shockwave shows regression of osteoarthritis of the knee in rats. Journal of Surgical Research, 171(2): 604-611.

19. Kim JH, Kim JY, Choi Cet al. (2015): The Dose-Related Effects of Extracorporeal Shock Wave Therapy for Knee Osteoarthritis, Ann Rehabil Med., 39(4):616-23.

20. Chen TW, Lin CW, Lee CL et al. (2014): The efficacy of shock wave therapy in patients with knee osteoarthritis and popliteal cyamella. Kaohsiung Journal of Medical Sciences, 30(7): 362-70.

21. Imamura M, Alamino S, Hsing TW et al. (2017): Radial extracorporeal shock wave therapy for disabling pain due to severe primary knee osteoarthritis. Journal of Rehabilitation Medicine, 49: 54-62.

22.Lee JH, Lee S, Choi S et al. (2017): The effects of extracorporeal shock wave therapy on the pain and function of patients with degenerative knee arthritis. The Journal of Physical Therapy Science, 29(3):536-8.

23. Elerian A, Ewidea $T$ and Ali N (2016): Effect of shock wave therapy versus corticosteroid injection in management of knee osteoarthritis.Int J Physiother., 3(2):246-51.

24. Wang CG, Wang FS, Yang KD et al. (2003): Shockwave therapy induces revascularization at the at the tendon-bone junction. A study in rabbits. J Orthop Res., 21: 984-989. 